Systems and software

Elsevier Editorial System(tm) for Journal of

Manuscript Draft

Manuscript Number: JSS-D-05-00149R1

Title: The mechanisms of project management of software development.

Article Type: Research Paper

Section/Category:

Keywords: software development; project management; project monitoring; project control; project coordination; empirical study

Corresponding Author: Mr Tom McBride,

Corresponding Author's Institution: University of Technology, Sydney

First Author: Tom McBride

Order of Authors: Tom McBride

Manuscript Region of Origin:

Abstract: The changing environments of software development such as componentbased, distributed and outsourced software development require matching changes by project managers to monitor, control and coordinate their projects. While the objectives of project management may be well established, the mechanisms with which those objectives are achieved are less well known. An empirical study was undertaken to investigate which mechanisms were used by practising project managers to monitor, control and coordinate software development projects. First, the types of mechanisms are discussed so that the mechanisms can be classified usefully. Then, the design of the empirical study is described. The data were collected through structured interview, which provided both quantitative and qualitative data. The data are analysed for each mechanism separately and the findings presented. The study found that project managers use multiple mechanisms to achieve project management objectives and use the same mechanism to serve multiple objectives. Further research is suggested to investigate project management from the opposite orientation, that is, which objectives are served by specific project management mechanisms. 


\title{
The mechanisms of project management of software development.
}

Tom McBride ${ }^{*}$

Faculty of Information Technology, University of Technology, Sydney, Australia

\begin{abstract}
The changing environments of software development such as component-based, distributed and outsourced software development require matching changes by project managers to monitor, control and coordinate their projects. While the objectives of project management may be well established, the mechanisms with which those objectives are achieved are less well known. An empirical study was undertaken to investigate which mechanisms were used by practising project managers to monitor, control and coordinate software development projects.

First, the types of mechanisms are discussed so that the mechanisms can be classified usefully. Then, the design of the empirical study is described. The data were collected through structured interview, which provided both quantitative and qualitative data. The data are analysed for each mechanism separately and the findings presented. The study found that project managers use multiple mechanisms to achieve project management objectives and use the same mechanism to serve multiple objectives. Further research is suggested to investigate project management from the opposite orientation, that is, which objectives are served by specific project management mechanisms.
\end{abstract}

Keywords: software development; project management; project monitoring; project control; project coordination; empirical study

\section{Introduction}

As software development projects adapt to changing circumstances, management of those projects must also adapt. Such changes could involve adopting different development life cycles, moving to component-based software development or distributing the development. While the project management objectives may remain the same, the mechanism used to achieve those objectives will not necessarily remain unchanged and adaptation would be assisted through understanding which mechanisms are used in different circumstances. Such knowledge of the mechanisms could guide the ways in which project managers adapt to different project environments as well as guide efforts to develop project workflow and project management tools.

This research investigates the mechanisms of project monitoring, control and coordination during the project's development phase. It concentrates on the development phase because that is when the project is subject to the unexpected events and external influences that require the project manager to take action to keep the project moving toward its objectives. It does not investigate project planning or any other activity that might be undertaken by the project manager prior to the start of actual software development because project management during that phase is concerned with producing the project plan, not developing the software. Nor does the research investigate activities undertaken after the software's development such as deployment or support and maintenance for similar reasons. Concentrating on the development phase means that project managers of all projects are likely to consider the same

\footnotetext{
* Corresponding author. Tel +612 9514 4528; fax +6129514 4535

email: mcbride@it.uts.edu.au
} 
range of project management mechanisms, the choice of which is likely to be subject to a similar range of influences.

\section{Project monitoring}

Project monitoring is the gathering of information to determine the current state and progress of the project in relation to its expected state and progress (Shumate and Snyder, 1994; AlJibouri, 2003; Navon and Goldschmidt, 2003). Frequently, project monitoring supports project control and is so frequently associated with project control that the two are treated as inseparable (Davies and Saunders, 1988; Hughes and Cotterell, 1999; Cleland and Ireland, 2002; OGC, 2002; Burke, 2003). Yet project monitoring and project control are not the same activity, nor are they inseparable. Control involves directing efforts toward some end objectives (Ouchi and Maguire, 1975; Eisenhardt, 1985; Kirsch, 1996) and sometimes considers information gathering to be part of the control activities. While this is a useful view when studying organizational control, it excludes information gathering for other purposes such as quality assurance (Shumate and Snyder, 1994; Kitchenham, 1996; Fenton, 2000; McGarry et al., 2002) or coordination (Crowston, 1991; Kraut and Streeter, 1995; Carmel, 1999; Faraj and Sproull, 2000; Zhuge, 2002; Sabherwal, 2003).

In this discussion, it is useful to separate monitoring from both control and coordination so that monitoring mechanisms can be identified independently of the intended use of the information, and so that the effect of organizational distance on monitoring can be considered independently.

A search of the literature revealed that monitoring mechanisms seem to fall into four groupings:

- Automatic monitoring. Information that can be gathered automatically from software development or project management tools and systems.

- Formal monitoring. Information that is gathered through a formal administrative system

- Ad hoc monitoring. Information gathered through irregular enquiry such as audits and reviews.

- Informal monitoring. Information gathered informally through conversations or their equivalent.

The groupings reflect the same separation based on fixed and variable costs that was proposed by Sabherwal (2003) for project coordination (Figure 1). Fixed costs are those costs incurred to establish the mechanism and would include such costs as initial purchases, training, installation and configuration of any required tools. Variable costs are those costs that are incurred each time the monitoring activities are performed. The more formal monitoring activities tend to incur higher fixed costs because people must be trained in their use, but lower variable costs. Informal and ad hoc monitoring mechanisms such as face to face meetings or tele-conferences tend to require little or no training but incur the same expense each time.

\section{Project Control}

Organizational control is exercised through actions taken to move the organization toward its objectives (Ouchi and Maguire, 1975; Eisenhardt, 1985; Flamholtz et al., 1985; Kirsch, 1996). The scope of theoretical work on organizational control is normally the entire organization. However, nothing in the established theories requires a minimum size of organization or particular type of organization. Thus, it is valid to apply theories of control to a project team. Restricting the scope of control to that of a project within the organization retains the sense that control relates to efforts made or actions taken to move the project toward its objectives 
(Kerzner, 1998; Hughes and Cotterell, 1999; Project Management Institute, 2000; Raffo et al., 2000; Cleland and Ireland, 2002).

There appear to be two main bodies of knowledge that deal with the problem of organizational control: control theory and agency theory. Organizational control theory concerns "attempts by the organization to increase the probability that individuals and groups will behave in ways that lead to the attainment of organizational goals" (Flamholtz et al., 1985). Organizational control theory is very general, applying to any organization in any circumstance. In contrast, agency theory (Eisenhardt, 1989) considers the problem of organizational control in the specific circumstance where an agent is carrying out work on behalf of a principal, such as may occur when work is sub-contracted or outsourced.

Ouchi (1979) studied organizational control mechanisms, identifying three types: market, bureaucratic and clan mechanisms. Ouchi proposed that the choice of control mechanism depended on knowledge of the transformation process and the ability to measure outputs. Eisenhardt $(1985 ; 1989)$ later examined the role of control in agency theory using Ouchi's model but extended it to include the agent's attitude to risk. This resulted in a model that predicted whether outcome control or behaviour control would be favoured. Henderson and Lee (1992) found that, within information system (IS) design teams, behaviour control and outcome control would coexist within the same project. The project manager exerted behaviour control while the team itself exerted outcome control within the team. Kirsch (1996) investigated the use of different control mechanisms in IS development but, in contrast to Henderson and Lee, focussed on relations between the project controller and the project team. It is not clear whether the term "project controller" used by Kirsch refers to the project manager who is part of the project team or to a manager external to the development team such as a client. Hamilton and Kashlak (1999) examined a multinational corporation's selection of a subsidiary's control system under various host country's conditions. They extended the contingencies to include the host financial policies, cultural distance and political restrictions in addition to the task programmability and output measurability used by Ouchi $(1975 ; 1979)$. The control mechanisms used by Hamilton and Kashlak in their analysis were output, behaviour and input control where input control was similar to, but not the same as, clan control (Ouchi, 1979, also Section 2.3.2.3).

The four types of control mechanism thus far identified are:

- Output Control: Exercised by measuring and rewarding results without concern for how those results were obtained.

- Behaviour Control: Achieved through prescribing behaviour to be followed is referred to as behaviour control (Ouchi and Maguire, 1975).

- Clan Control: Exercised through adherence to shared values. When tasks are inherently ambiguous, and a precise description of how the task is to be performed is impossible, control is exercised through shared beliefs about how the work should be performed (Ouchi, 1979).

- Input control: Exercised through recruitment and training. (Hamilton and Kashlak, 1999)

\section{Project Coordination}

Coordination is concerned with managing the interdependencies between activities (Malone and Crowston, 1994) or among multiple individuals involved in an activity (Kraut and Streeter, 1995). The purpose of coordination, as Kraut and Streeter point out, is to "coordinate the work so that it gets done and fits together, so that it is not done redundantly, and so that the components of the work are handed off expeditiously."

The most frequently cited definition of coordination is that of Malone and Crowston (1994) in which coordination is defined as "managing the dependencies between activities". Their 
analysis considers shared resources, producer/consumer relationships, simultaneity constraints and task/subtask dependencies. Thus, their model considers the relationships between actors, actions, the acted upon and the constraints that may operate on combinations of all three.

Sabherwal (2003) examined prior literature to arrive at a broad classification of coordination mechanisms into plan, standard, formal mutual adjustment and informal mutual adjustment. The mechanisms identified by Sabherwal are distinguished by their fixed and variable costs. The more formal coordination mechanisms have higher initial costs but lower variable costs. The less formal mechanisms have a lower initial cost but higher variable costs as illustrated in Figure 1.

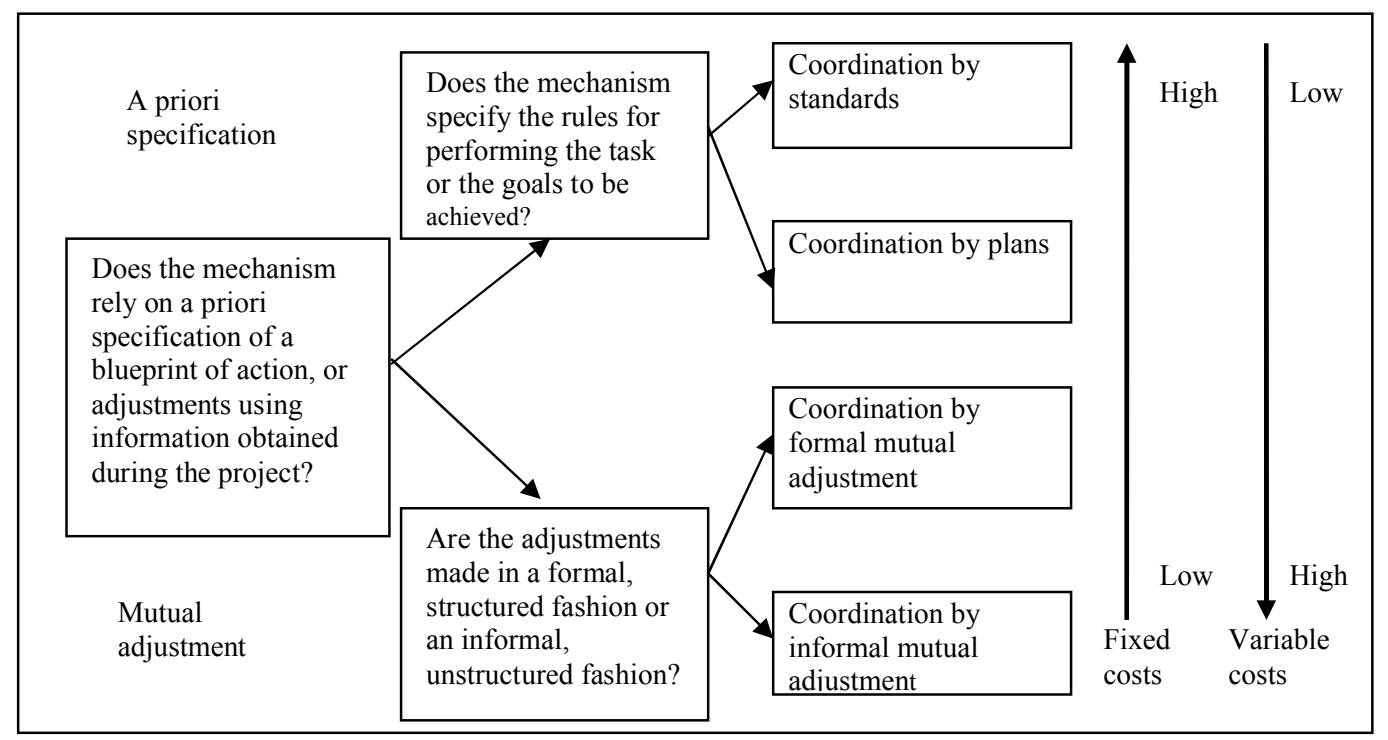

Figure 1: The classification of coordination mechanisms - from Sabherwal (2003)

The available models of coordination (Adler, 1995; Nidumolu, 1996; Andres and Zmud, 2002; Sabherwal, 2003) all display some form of continuum from more formal and less interactive to less formal and more interactive. Since this research needs to identify the different coordination mechanisms rather than deal with an undifferentiated group of mechanisms, it will adopt the classifications proposed by Sabherwal as a result of considering the body of research concerning coordination mechanisms; that is, plan-based, standards-based, formal mutual adjustment and informal mutual adjustment.

- Coordination by standards. The distinguishing feature of this type of mechanism is that it is concerned with the rules by which something is done rather than the goals that guide the development (Sabherwal, 2003).

- Coordination by plans. When coordination is achieved by specifying what is to be produced and, possibly, when it is to be produced, then this can be described as coordination by plans (Sabherwal, 2003).

- Coordination by formal mutual adjustment. Overcoming some problems requires some form of mutual adjustment, some of which can be formalized into specific actions or mechanisms. Kraut and Streeter (1995) offer modification request tracking and data dictionaries as examples of formal mutual adjustment. Sabherwal (2003) additionally lists design review meetings, reporting requirements and liaison roles among the formal mutual adjustment mechanisms. 
- Coordination by informal mutual adjustment. Informal mutual adjustment is the most flexible all the types of coordination mechanisms but comes with a high variable cost (Sabherwal, 2003).

\section{Which mechanisms do project managers use?}

So far, it is difficult to find information about which mechanisms project managers actually use. There has been investigations into control mechanisms used in information systems design (Henderson and Lee, 1992), the evolution of a portfolio of control mechanisms over the life of a software development project (Choudhury and Sabherwal, 2003), as well as the more theoretical research into the influence of national cultures on the selection of control mechanisms (Hamilton and Kashlak, 1999). Selection of project coordination mechanisms has been investigated in relation to risk (Nidumolu, 1996) and the type of coordination mechanism (Andres and Zmud, 2002). The evolution of coordination mechanisms (Sabherwal, 2003) has also been investigated. Kraut and Streeter (1995) examined the more general aspects of how coordination was achieved in software development but any investigation into project monitoring mechanisms is difficult to find.

Thus, the research question is;

RQ1: Which mechanisms do project managers use to monitor, control and coordinate software development projects?

It is useful to divide this research question into three so that monitoring, controlling and coordination can be investigated separately.

RQ1.1: Which mechanisms do project managers use to monitor software development projects?

RQ1.2: Which mechanisms do project managers use to control software development projects?

RQ1.3: Which mechanisms do project managers use to coordinate software development projects?

\section{Research design}

The research data were gathered by interviewing software development project managers, guided by the research instrument. The interviews were audio recorded, transcribed and checked by the interviewed project manager.

The chosen data collection method of structured interview used questions designed to yield both quantitative data and qualitative data.. Questions and responses can be clarified, new information provided and accepted. More of the subject's general knowledge can be elicited than is possible with other techniques, and interviews can expose issues that the subject had not thought of previously (Seaman, 1999; Wood et al., 1999).

This ability to clarify a question or a response was attractive since questions that appear very clear to the researcher are not always clear to the subject. Some questions, such as those designed to characterise the organization, are more amenable to providing a list of possible responses and could have been given in a survey. Generally, such topics have a known range of responses and it is possible to develop a set of categorical or quantitative responses from which the respondent is expected to choose. However, other information could only have been sought through an open question where the interviewer must work hard to avoid imposing their view of both the question and the expected responses (Yin, 2003 p61).

\section{Research instrument}

The questionnaire that guided the structured interview, was based on assessment models and data collection methods used in SPICE assessments (International Standards Organization, 
2004). The questionnaire was made up of 49 questions developed by identifying the constructs needed for the research, then devising questions to gather data for the constructs. The questions were then allocated to a question category that related to the subject area so that questions could be asked in logical groupings and the interview could deal with each subject area without having to return to it. The interview questions were then linked to a research question so that the interview questions could be reported by research question or by construct. Listing them in the different ways permitted checking that each construct and research question was adequately covered and that there was not an undue concentration in any one area. Some interview questions would provide information that related to more than one research question.

A list of possible or probable responses was developed for each question. When the question sought an ordinal response, an ordinal scale of responses was developed. When the question sought nominal information, a list of the more expected responses was developed. This aided note-taking during the interview and added context to the question so that if the subject found the question ambiguous there was additional information available to clarify it. For example, the first question sought a measure of the size of the project, an ordinal measure. A question on the type of system being developed listed the industry sectors for which, from the researcher's experience and knowledge of the local software development industry, software was developed (Table 1).

Table 1: Example questions from the structured interview script showing an ordinal scale of responses and a nominal list of potential responses.

5 How large is your project(s). The measure of size could be one of budget, number of requirements or function points, or planned effort or duration? The purpose of the question is to have some way to separate projects into large, medium or small projects.

Small - $<6$ months, $\$ 100 \mathrm{~K}$

Medium - 1 year $<\$ 1 \mathrm{M}$

Large - $>1 \mathrm{M}$

$6 \quad$ What type of system is being developed?

Financial, ERP, CRM, SRM

Military

Infrastructure

Telecommunications

Medical

Transport

Services

Factory automation

Other

Specific terminology used in this research do not necessarily mean the same thing to all project managers. For example, to one project manager the term "project monitoring" might mean only those activities that directly seek information while to another it might mean all activities that yield information about the project. For this reason, project managers were not directly asked "How do you monitor your projects?" but were, instead, asked how they dealt with a situation. Their responses yielded information on project monitoring, project control and project coordination.

The total number of questions was constrained by the time that it was thought each interview would take. While most people are prepared to spend up to an hour on a research project such as this, asking for more than one hour of their time was thought likely to discourage

participation. 


\section{Conducting the interviews}

Interviews were mostly conducted at the subject's premises and at a time convenient to them. The research was introduced and described; then the subjects were asked to sign the consent form that explained the researcher's obligations. Permission was sought from each participant to record the interview. All participants agreed to this request and even though the offer was made to turn the recorder off during the interview, only one subject requested that be done for a brief period.

Each interview lasted between twenty minutes to just over one hour. The duration depended on how much detail the subject wanted to provide. At the end of the interview, subjects were told that the recorded interview would be transcribed and emailed to them for checking. The objective of checking was to have the transcript say what they wanted to say rather than to be a literal record of the interview. This was to allow a subject to change their answer if, after reflection, they thought of additional information or a better way to express their answer. It also afforded the opportunity to change an answer they found embarrassing once they saw it in print. None of the subjects altered a response for this reason.

Each interview was transcribed as soon after the interview as possible to preserve and to overcome audibility problems that can sometimes make it difficult to hear precisely what was being said. Generally, transcribing was completed within the same week. Each interview took between 3 and 6 hours to transcribe and averaged 10 pages in length. There were 321 pages of transcript in total.

Recording and transcribing the interviews also provided considerable raw data for content analysis, giving a different view of the same interview. Multi-method research helps to overcome the perceived weaknesses in single-shot approaches (Wood et al., 1999). Using the two different views of the data, a quantitative survey response and a content analysis, is not as strong as would be analysis of two separate sets of data gathered by different research techniques, but is claimed to be stronger than either one of the techniques used separately.

\section{Sample selection}

Subject selection used a combination of self selection and accidental selection. An initial list was drawn up of organizations located in Sydney and known to develop software. Each organization was phoned and a request was made to speak to a project manager. Accidental selection was performed through phoning organizations listed in the "Computer Software and Packages" section of the Sydney Yellow Pages. No record was kept of how many organizations were approached. However, after reviewing the retained section of the Yellow Pages, I estimate that approximately 400 organizations were approached. Thirty two interviews were conducted with people from twenty eight organizations. The acceptance rate is approximately $7 \%$.

\section{External validity}

External validity is the extent to which the findings may be generalised to other contexts (Leedy and Ormrod, 2001). The sample size of 32 project managers belonging to 28 different organizations is small for quantitative research. While it may be large enough to perform some simple statistical tests such as Pearson's correlation or a Chi-square test, it is not large enough for any multivariate analysis. Even within the sample, some of the tests did not have sufficient occurrences in each category to get a result. Therefore, the findings of this research are not considered generalizable but may be a useful of further research. 


\section{Analysis.}

The first type of data is the question responses encoded according to the devised response scale or category. These data are amenable to statistical analysis. The second set of data comes from content analysis of the interview transcripts. These, too, are amenable to quantitative analysis. The third set of data is the interview transcripts themselves, which can be examined qualitatively for themes that contribute to understanding the research question. Yin (2003) argues that case study data analysis, by following the theoretical propositions and by testing rival propositions, are stronger analytical strategies than the third strategy of developing a descriptive framework with which to organize the data.

Content analysis most commonly counts the frequency with which something is mentioned as indicating its importance (Lacity and Janson, 1994). This analysis seeks to identify the different mechanisms used by project managers to monitor, control or coordinate their projects. Of interest was the number of the different project management mechanisms rather than any indication of importance accorded them by the project manager.

Each interview is a small, albeit narrow, case study (Yin, 2003) conducted to explore the research question that the choice of project management mechanisms will depend on the organizational distance between the project manager and elements of the project team. Each interview is examined for themes that support the research question, or that support possible rival propositions.

Qualitative analysis is better able to reveal the reasons for actions, why a decision was made or a project management mechanism was chosen, and to give depth and meaning to a complex situation (Leedy and Ormrod, 2001). While this research primarily investigates which project management mechanisms are used and the relationship between organizational distance and the use of project management mechanism, augmenting the quantitative analysis with qualitative analysis may give a deeper understanding of the results.

\section{Project monitoring}

This part of the analysis investigates the second sub-question. That is:

RQ1.1: Which mechanisms do project managers use to monitor software development projects?

The analysis will be performed using data from both the structured interview "check list" responses and from the content analysis of the interview transcripts. Data from each will be presented separately so that the origins of inferences are clear. Some conclusions will be drawn about which mechanisms are preferred.

\section{Structured Interview data}

Project managers were asked how they established that the project was "on track" and, in a separate question, how they detected that the project was "not on track". The responses were grouped as shown in Figure 2. The data indicate that expert judgement and various progress measures are used significantly more than other measures such as earned value or test data. 


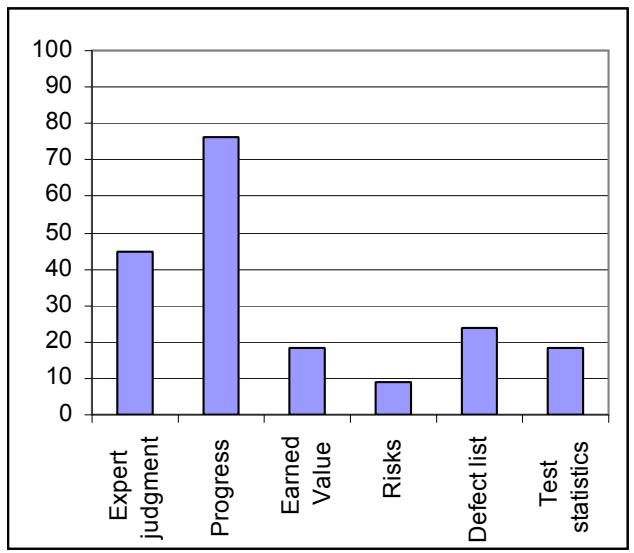

Figure 2: Project manager responses to the question of how they established the project was "on track".

\section{Content analysis}

Project managers might use different mechanisms to determine project progress, for example, so the interview transcripts were examined to determine what type of mechanism was used to monitor the project. Project managers could employ multiple monitoring mechanisms on the same project. In order for more than one monitoring mechanism of the same type used by the same project manager to be counted, there needed to be clear indications that the implementation of the mechanism was separate. For example, projects often have team meetings and formal meetings with the organization's management. Both are formal monitoring mechanisms and if a project manager indicated that both were used then the count of formal monitoring mechanisms was two. However, if the project manager simply referred to "meetings" and did not distinguish team meetings from management meetings, then only one formal monitoring mechanism was recorded.

Table 2: Frequency of monitoring mechanisms detected with content analysis.

\begin{tabular}{|l|l|c|c|}
\hline \multirow{2}{*}{ Monitoring mechanism } & Count & Percent \\
\hline \multirow{4}{*}{ Automatic } & CSCW, Workflow & 2 & 6.3 \\
\cline { 2 - 4 } & Configuration management & 6 & 18.8 \\
\cline { 2 - 4 } & Defect, issue tracking & 9 & 28.0 \\
\cline { 2 - 4 } & Automated integration \& testing & 3 & 9.4 \\
\cline { 2 - 4 } & Release management & 12 & 37.5 \\
\cline { 2 - 4 } & Development cycle & 11 & 34.4 \\
\cline { 2 - 4 } & Project bulletin board & 1 & 3.1 \\
\hline Formal & Product review/inspections & 6 & 18.8 \\
\cline { 2 - 4 } & Schedule \& milestone tracking & 30 & 94.0 \\
\cline { 2 - 4 } & Team meetings & 30 & 94.0 \\
\cline { 2 - 4 } & Status reports & 28 & 87.0 \\
\cline { 2 - 4 } & Management review & 24 & 75.0 \\
\cline { 2 - 4 } & Customer review & 10 & 31.0 \\
\hline \multirow{4}{*}{$\begin{array}{l}\text { Ad hoc } \\
\text { monitoring }\end{array}$} & QA or process audit & 6 & 18.8 \\
\cline { 2 - 4 } & Phase end review & 9 & 28.0 \\
\cline { 2 - 4 } & Drill down inquiry & 20 & 62.5 \\
\hline \multirow{3}{*}{$\begin{array}{l}\text { Informal } \\
\text { monitoring }\end{array}$} & Conversations with project team & 9 & 28.0 \\
\cline { 2 - 4 } & Conversations with stakeholders & 18 & 56.0 \\
\cline { 2 - 4 } & Conversations with customer & & \\
\hline
\end{tabular}




\section{Qualitative analysis.}

Project managers' views of what it meant to monitor a project and how they achieved it was largely contained in the responses to questions 16,17 and 18 of the questionnaire.

Almost without exception, project monitoring is seen as a process of maintaining awareness of progress through the planned schedule. Less frequently, project managers maintained an awareness of any threats to progress through their monitoring activities. Data on the completion of scheduled tasks was gathered in a number of ways: verbal reports during team meetings, written reports submitted by the team member, updating a common file and, sometimes, casual conversations. In some of the larger organizations, team members appeared to have submitted their reports to an administration assistant who then prepared a report for the project manager.

The structured interview questions dealt with knowing whether the project was "going right" or "going wrong" to establish which information, of all the information the project manager may receive in a given period, they most used in order to determine the state of the project. The most common response was that the project's progress was checked against expected progress. For some, this was determined by task completions, for some by earned value and for some by milestone completion.

\section{Findings}

- The majority of project managers monitor their projects through the formal mechanisms of team meetings and schedule tracking. This is supplemented with informal conversations with the project team, afforded by co-location, and conversations with the customer.

- The majority of project managers use multiple monitoring mechanisms to track the status of the project.

- Project managers do not consciously use automated monitoring to any significant extent. Similarly there are a number of mechanisms such as phase end reviews, design reviews and project bulletin boards that are used by a minority of project managers. While these mechanisms may be essential in some circumstances and prove very valuable, their use is not widespread as a means of monitoring the project.

\section{Project control}

This part of the analysis investigates the second sub-question. That is:

RQ1.2: Which mechanisms do project managers use to control software development projects?

Project control seeks to ensure that people act in a way consistent with achieving the desired objectives (Choudhury and Sabherwal, 2003). Project managers normally have the three objectives of schedule, functionality and quality to juggle by sacrificing one to achieve the others. This research added system performance to the list of objectives because there are some systems, for example real time control systems, where performance is just as important as functionality.

The structured interview questions took a simple view of project control. Project managers were asked how the organization prioritised their success criteria and how the project manager exercised project control in response to delays in project task completion. The content analysis sought evidence of the different types of control mechanisms project managers employed during the project. Thus, the analysis of the data from the structured interviews focussed on what the project manager did to control the project while the content analysis focussed on the mechanisms with which they did it. 
Project managers were asked what they would do when some event delayed the completion of a task. This is a normal decision faced by project managers when one or more of the project tasks is taking longer than expected or is more difficult to implement than expected.

Sometimes functionality, quality or performance is retained at the expense of the schedule. The most common response in this research was that the decision depended on the situation. The frequency of the different responses is shown in Figure 3.

Performance targets for the software being developed were either not set (15\% of responses) or always retained ( $27 \%$ of responses). A more correct interpretation of "always retained" would be that performance wasn't knowingly compromised to achieve other project or product objectives. Frequently the initial response was surprise because performance, in terms of system throughput, is seldom specified and is not usually thought of as something that can be traded against project schedule. During the interviews, it was explained that system performance might have been expressed as a required response time or a required transaction throughput. The clarification seldom altered the respondent's answer.

Quality targets were also rarely knowingly compromised to meet schedule commitments. Project managers did acknowledge that they would sometimes deliver a release with reduced quality (more defects than expected) when it could be followed up with a "patch release" that rectified the defects.

Most of the time it was functionality that was traded against project schedule, as illustrated in Figure 3 . When negotiating project objectives with the project stakeholders, it is functionality that is most often negotiated.

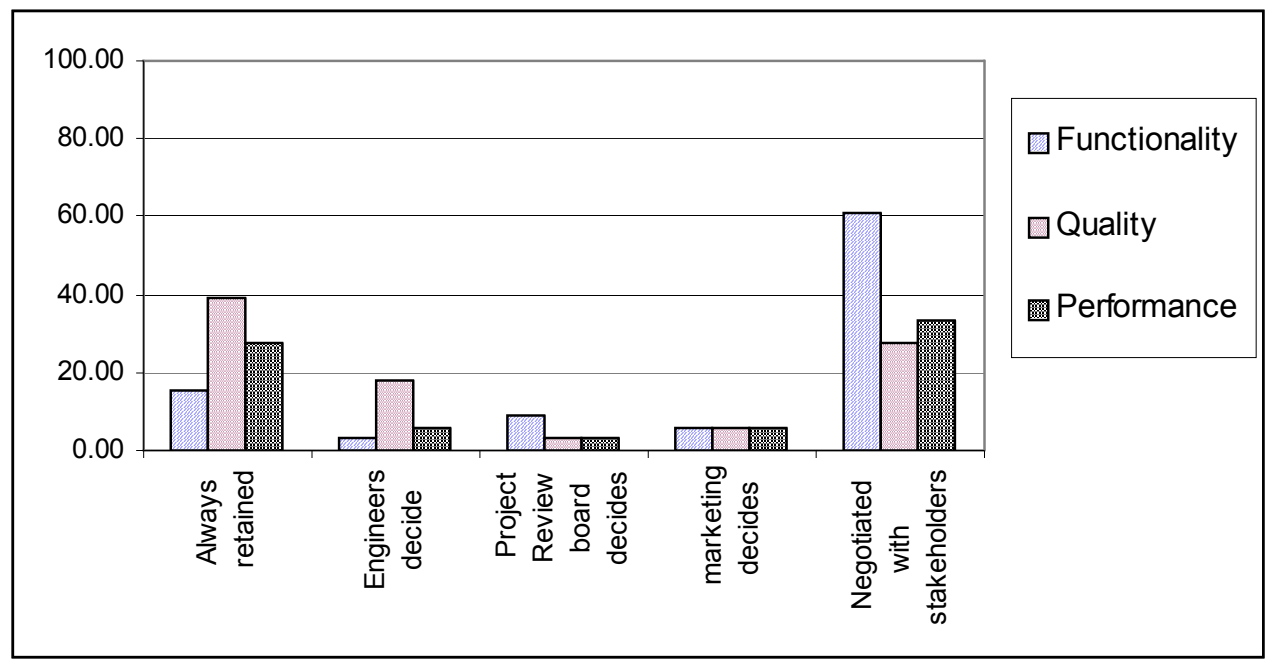

Figure 3: Trade-off between functionality, quality and performance over schedule when the schedule is threatened

\section{Content analysis}

To gain a different perspective of project control mechanisms, the interview transcripts were examined for evidence that project managers used different types of control mechanisms. The classification of the mechanism types and reasons for their selection has previously been discussed. Briefly, the types of control mechanisms are output, behaviour, input and clan control. The frequency with which specific control mechanisms were mentioned in the interview transcripts is given in Table 3. 
Table 3: Frequency of control mechanism used by software development project managers.

\begin{tabular}{|l|l|c|c|}
\hline \multicolumn{2}{|l|}{ Control mechanism } & $\begin{array}{l}\text { Coun } \\
\mathrm{t}\end{array}$ & Percent \\
\hline Output Control & Budget, schedule, functionality & 28 & $87.5 \%$ \\
\hline \hline & Customer satisfaction & 18 & $56.3 \%$ \\
\hline \hline & Contract T\&C & 12 & $37.5 \%$ \\
\hline $\begin{array}{l}\text { Behaviour } \\
\text { Control }\end{array}$ & Other output control & 23 & $71.9 \%$ \\
\hline \hline & Formal processes & 22 & $68.8 \%$ \\
\hline \hline & Process training & 10 & $31.3 \%$ \\
\hline & Project Plan & 32 & $100.0 \%$ \\
\hline \hline & Other Behaviour control & 2 & $6.3 \%$ \\
\hline \hline & PM selection & 2 & $6.3 \%$ \\
\hline & Team selection & 7 & $21.9 \%$ \\
\hline & Select by RFP & 3 & $9.4 \%$ \\
\hline & Other Input control & 4 & $12.5 \%$ \\
\hline & Team co-location & 24 & $75.0 \%$ \\
\hline \hline & Exchange developer & 1 & $3.1 \%$ \\
\hline \hline & Site visits by PM or team & 14 & $43.8 \%$ \\
\hline & Informal communication & 20 & $62.5 \%$ \\
\hline & Other clan control & 1 & $3.1 \%$ \\
\hline
\end{tabular}

Of the output control mechanisms, the most frequently used is some combination of budget, schedule and functionality that is normally part of the project's general objectives. This is not surprising since those objectives, or constraints, drive project planning. The frequency or "other output control" is made up of; acceptance testing or other form of formal testing (12 instances), a financial measure over and above meeting the project's budget such as "profitability"(5 instances) or some measure of organizational target such as meeting Key Performance Indicators or KPI (7 instances).

Of the behaviour controls, the project plan is used without exception. The data does not distinguish between different types of project plan nor is there any measure of the project plan's granularity. Nevertheless, the universal use of a project plan indicates a wide consensus on its value as a control mechanism.

Project managers were asked directly if they, or their organization, used formal development processes. The processes that were considered to qualify as "formal" did not need to be those that would meet the requirements of an ISO 9001 audit but did have to be formally expressed in some way. None of the project managers indicated that the project teams ignored the formal development or quality processes. This contrasts with anecdotal claims by some of the interviewed project managers that development methodologies and quality management systems tend to be ignored by software developers.

Team co-location usually meant that the team was in one place rather than dispersed. Frequently, the development teams were located on the customer's premises, even if that was overseas.

Informal communication is a very general category and is normally taken to mean casual conversations but it also included emails and phone conversations (Kraut and Streeter, 1995; Sabherwal, 2003). The essential characteristic of informal communication is that it is unplanned and unrestricted and not that it occur face to face. 


\section{Qualitative analysis}

Project managers perceived control to be something they actively did rather than something structured during project planning. For example, team co-location was seen as a way to better understand the client's requirements rather than as a way to control the client or the project team. Even in response to specific scenarios set out in the questionnaire, project managers reported that they tended to control the project by direct actions aimed at keeping the project on schedule. None of the project managers responded with something longer term such as moving the team to the customer's premises, an action Sabherwal found when considering the evolution of project coordination mechanisms over the life of a project (Sabherwal, 2003).

Contract terms and conditions or development life cycles (shown in Table 3) are more structural in nature and were seen more as organizational than project management matters. When dealing with outsourced development, project managers occasionally travelled to the supplier's site but is was normal to talk to them regularly. Although this was normally part of, or intended to be, a way to establish the project status, it also served as a form of clan control.

\section{Findings}

- All project managers controlled the behaviour of their development teams through a project schedule, commonly referred to as the "project plan". Formalised, that is documented, software development processes were also a common mechanisms to control behaviour in almost $70 \%$ of projects.

- The majority of project managers reported that their project was controlled by the project objectives, commonly functionality, budget and delivery date. The majority of project managers were also subject to additional project objectives which could be financial or organizational.

- Co-location and informal communication were employed by a majority of project managers as a means of clan control but the choice of mechanisms in this category were less distinct than in the other categories of control types.

- Project managers commonly employed a portfolio of control mechanisms to control the project rather than rely on one type of control mechanism.

\section{Project coordination}

This section of the analysis investigates the third research sub-question. That is:

RQ1.3: Which mechanisms do project managers use to coordinate software development projects?

Project team meetings are common in software development and are one of the more frequently used coordination mechanisms. The structured interview did not explore different methods of holding meetings such as video conference or "in person" but did explore the purpose of team meetings and management meeting through the subjects that were discussed. Very few project managers, less than $10 \%$, do not hold regular team meetings. In the research sample, those that did not hold team meetings were teams of one person, where team meetings are inappropriate.

Table 4: Subjects discussed at team meetings.

\begin{tabular}{|l|c|c|}
\hline & Count & Percent \\
\hline Team meetings are held & 29 & 90.6 \\
\hline Design & 18 & 56.3 \\
\hline Requirements & 15 & 53.1 \\
\hline Schedule, budgets, milestones & 26 & 81.3 \\
\hline Risks and issues & 12 & 62.5 \\
\hline Other & 11 & 34.4 \\
\hline
\end{tabular}


While the data indicate that schedules, budgets and other matters related to project progress are discussed more frequently at team meetings ( $81 \%$ of cases), other topics are not neglected. Team meetings appear to act as a general discussion forum rather than be devoted to a single topic.

\section{Content Analysis}

A more granular view of project coordination mechanisms reveals that project coordination is achieved through more than team meetings. The interview transcripts were examined for evidence of coordination mechanisms that were then classified according to the previously established scheme of standards-based, plan-based, formal mutual adjustment and informal mutual adjustment. The frequency of each type of coordination mechanism is displayed in Table 5.

Table 5: Frequency of coordination mechanisms detected through content analysis.

\begin{tabular}{|l|l|c|c|}
\hline \multicolumn{2}{|l|}{ Coordination mechanism } & Count & $\%$ \\
\hline Standards based & Template work products & 16 & 50 \\
\cline { 2 - 4 } & Interface specs & 6 & 19 \\
\cline { 2 - 4 } & Design rules & 6 & 19 \\
\hline \multirow{4}{*}{ Plan based } & Schedule & 27 & 84 \\
\cline { 2 - 4 } & Specifications & 32 & 100 \\
\cline { 2 - 4 } & Sign offs - phase reviews & 11 & 34 \\
\cline { 2 - 4 } & Test plans & 17 & 53 \\
\hline \multirow{4}{*}{$\begin{array}{l}\text { Formal mutual } \\
\text { adjustment }\end{array}$} & Code and design reviews & 7 & 21 \\
\cline { 2 - 4 } & Change control committee & 11 & 34 \\
\cline { 2 - 4 } & Project team meetings & 28 & 87 \\
\cline { 2 - 4 } & Ad hoc meetings & 17 & 53 \\
\cline { 2 - 4 } & Project reviews & 14 & 43 \\
\hline Informal mutual & Co-location & 19 & 60 \\
\cline { 2 - 4 } & $\begin{array}{l}\text { Management by walking } \\
\text { about (MBWA) }\end{array}$ & 11 & 34 \\
\cline { 2 - 4 } & Personal conversation & 25 & 78 \\
\cline { 2 - 4 } & Site visits & 14 & 43 \\
\hline
\end{tabular}

It is notable that four mechanisms are used significantly more frequently: schedule, specifications, project team meetings and informal conversations. Co-location appears to be almost as popular. However, in this research sample only $46.9 \%$ of projects had some outsourced elements so it is reasonable that co-location would feature as a coordination mechanism in approximately $60 \%$ of projects. It's presence does not indicate a conscious use of co-location to manage the project.

The data indicate a very high incidence of schedules, specifications and project team meetings that indicates a trend toward market based mechanisms (Sabherwal, 2003).

The high use of formal and informal mutual adjustment mechanisms, team meetings and personal conversation, indicate a need to manage a significant amount of reciprocal dependency.

\section{Qualitative analysis}

While project coordination was seen by project managers as the actions they might take to realign the completion of documents or components, in fact all projects employed some form of specification that described what the various components were to do, and almost all project managers expressed a work breakdown schedule in some form of project plan. Coordination 
was seen as the actions taken to adjust the scheduled delivery of components or to adjust the effort involved in producing the components.

The larger or more time critical projects tended to used fairly detailed work breakdown structures, where tasks were broken down into something that could be completed in a week or less. There didn't appear to be a significant difference between large or small projects in the granularity of the work breakdown structure although there did appear to be a tendency for less rigour when the project iterated over many releases, possibly over several years. In such cases there was a ready mechanism to offload work that could not be completed in the current release. However, projects with less flexible delivery dates and less flexibility over delivered functionality tended to be planned in considerable detail.

\section{Findings}

- Project coordination is achieved by the majority of project managers through planbased mechanisms of product specifications and the project schedule. Phase reviews and test plans were used but not as extensively as plan-based mechanisms.

- The most popular standards based coordination mechanism, that of template work products, was reported to be used by $50 \%$ of project managers. Compared to the reported use of other mechanisms, such as schedules and specification, this does not represent a preferred coordination mechanism.

- Of the formal mutual adjustment mechanisms, the most favoured was the project team meeting. The only other formal mutual adjustment mechanisms reported by more than $50 \%$ of project managers was the ad hoc meeting. While other mechanisms were employed in some projects, their use does not indicate a strong preference.

- Informal mutual adjustment mechanisms were dominated by the informal conversation and by co-location. Management by walking about (MBWA) was the least favoured coordination mechanism.

- As with both project monitoring and project control, project managers employ a portfolio of project coordination mechanisms and do not constrain themselves to one or two mechanisms.

\section{Discussion}

The first research question was "Which mechanisms do project managers use to monitor, control and coordinate software development projects?" Data gathering and analysis sought to identify which project management mechanisms were used by project managers. It was found that some project management mechanisms are used more frequently than others. In some cases the usage pattern was quite distinct. A finding that was not anticipated was that project managers employ a portfolio of mechanisms rather than relying on a single mechanism. For example, a project manager does not rely on project meetings to monitor the project but will use multiple mechanisms to monitor the project.

\section{Project monitoring}

Project managers favour formal and informal monitoring mechanisms over automatic or ad hoc monitoring mechanisms. The most familiar monitoring mechanism is the weekly project review meeting with the development team that reviews the schedule and milestones as well as other project issues. There is little evidence of adopting such automated tools as CSCW or workflow systems but some evidence that iterative development is being used with its frequent release cycles permitting a form of automatic monitoring. Informal monitoring through conversations with the project team and with the customer is widely practised. One of the unexpected findings is that many project managers that use schedule and milestone tracking to monitor the general state of the project but supplement this with ad hoc "drill down" enquiries whenever there are any slippages or even threats of slippages. Such an early 
warning system of monitoring would appear to be an inexpensive and unobtrusive way to monitor the project and react quickly when needed.

\section{Early warning systems}

The analysis clearly showed that project managers used the formal project monitoring mechanisms as a warning system to indicate that something needs further investigation. If any alarm was triggered in the mind of the project manager then ad hoc monitoring was initiated in the form of a specific inquiry or something more formal such as a project audit. This is an efficient way to monitor any project. If the formal monitoring does not need to gather a lot of information then it can be pared down to only that which indicates the health of the project rather than having to include information that would indicate all the possible causes of ill health. Causes of "ill health" can be sought through a more directed inquiry that needs only involve those directly concerned with the particular problem and not the entire project team.

\section{Multiple sources of information}

Project managers tended to use multiple sources of information about the same aspect of the project. Mostly this was the project's progress, which could be measured reasonably clearly, but also included less measurable attributes, such as the project's health. This indicates that multiple sources of information will be sought to overcome information uncertainty. If the data cannot be readily verified by the project manager, then multiple sources of the same project attribute will triangulate the information, thus reducing uncertainty. If the project or product attribute is difficult to measure, then multiple related measures will tend to reduce the inaccuracy of single measures. For example, it is difficult to monitor a single project characteristic that would indicate the health of the project and the probability that it will be completed on schedule. Instead, several measures are sought that can collectively indicate the project's health. This research did not pursue this apparent relationship between information uncertainty and the number of information sources. That will be left for further research.

\section{Project Control}

What is notable about the controls is the dominant use of the project work breakdown structure and schedule, commonly referred to as the project plan. All project managers used some form of schedule based plan whether this was a simple "to do" list or a more elaborate project plan contained in a tool such as Microsoft Project.

With all the range of controls available, only a few are employed to any great extent. Control mechanisms used significantly more than other forms of control were: the main project objectives that would be part of the project's charter, development processes, a project plan, co-location and informal communications. Of the possible controls, team selection would seem to be used, but either not thought important or not drawn out by the research data gathering. Given the concentration on recruiting software development personnel with specific skills that is evident through the press ${ }^{\dagger}$ or the number of recruitment agencies that concentrate on the software development industry or the common practice of preparing a request for proposal (RFP), it is clear that control by recruitment is practised.

The portfolio of controls did not vary significantly over the organization size, project size, organizational process maturity or any other organizational or project attribute. This implies that the common portfolio of controls is very robust and widely applicable.

\footnotetext{
${ }^{\dagger}$ In Sydney there are three daily newspapers. Of these, two have an IT supplement on one weekday which normally includes a selection of jobs. Additionally, the Saturday edition of all newspapers frequently features a number of IT-related jobs.
} 


\section{Project Coordination}

Although there is clearly a preference for some coordination mechanisms over others, most available mechanisms are used. The coordination arising from the more formal aspects of project management, the specifications and the project schedule, appear to be almost universally used.

As with both monitoring and control, project managers employed several project coordination mechanisms. The plan-based mechanisms dominated but formal mutual adjustment and informal mutual adjustment were strongly supported.

This research indicated that more than $80 \%$ of all project managers used a project schedule and adjusted the project using the schedule, and all project managers used specifications to coordinate how the work was partitioned then integrated. Such significant usage of two different mechanisms in the one category of coordination mechanisms indicates that planbased coordination may have some advantages over other forms of coordination.

Coordination by formal mutual adjustment was most frequently achieved through project team meetings. Reviews, whether formal reviews of the project or internal design and code reviews, were not as frequently employed. The popularity of project team meetings is unsurprising since the interview questions asked specific questions about them whereas no questions sought information on design rules or interface specifications.

Of the informal mutual adjustment coordination mechanisms, the most frequently employed was personal conversation. This research did not seek the purpose for conversations, so further research is recommended to investigate the varying usage of project management mechanisms. Aside from conversations, the most popular information coordination mechanism was to co-locate the development team. Different forms of co-location were employed. Locating the entire development team close together and locating the development team on the customer's premises were the most common forms of co-location.

\section{Significance to project managers}

This research has identified that a range of mechanisms are available to project managers and has shown the relative popularity of each. Although the research has limited external validity due to the relatively small number of interviews, it is believed to be reasonably representative of the software development industry. The research suggests that not only are there many mechanisms to monitor, control and coordinate software development projects but that several of them might be employed on the same project. Certainly there was some indication that the more experienced project managers employed multiple mechanism to increase the richness of information available to them and to verify the consistency of the information.

The research did not extend to identifying which circumstances or project types tended to favour specific mechanisms. Instead this research simply seeks to identify current practice.

\section{Future research}

This research investigated the use of project management mechanisms by considering each type of mechanism (monitor, control and coordinate) separately then later observing that project managers frequently use the same mechanism for multiple purposes. This suggests that the opposite approach could be fruitful, i.e., to first establish which mechanisms project managers use and the different purposes for which they are used.

There has not been a rigorous analysis nor any empirical data on how any one mechanism is used by a project manager to achieve multiple objectives. Research to date has investigated project control (Zmud, 1980; Henderson and Lee, 1992; Kirsch, 1996; Addison and Vallabh, 2002; Choudhury and Sabherwal, 2003) or project monitoring (Kitchenham, 1996; Dumke and Winkler, 1997; Royce, 1998; Kitchenham et al., 2001) or project coordination (Kraut and Streeter, 1995; Crowston and Kammerer, 1998; Faraj and Sproull, 2000; Andres and Zmud, 
2002; Sabherwal, 2003) and has identified the mechanisms employed to achieve each separate objective. But many of the same mechanisms used for project control, for example, are also used to achieve project coordination.

A project management mechanism could be used for different objectives, depending on the circumstances. For example, a meeting may be used to enforce project control and, later, another meeting be used to clarify how some parts of the system must interact, which is a coordination matter.

More likely is that mechanisms will be used for several purposes at the same time. A mechanism may be used to achieve a primary objective as well as a secondary objective. For example, a specification such as a system design is primarily a control mechanism since it specifies what is to be achieved. However, the same specification acts as a coordination mechanism by specifying the how different parts of the system will interact.

The primary, secondary or incidental purposes for which a mechanism is used could vary according to circumstances and this would need to be investigated.

Understanding how the different mechanisms are used would reveal more about how project managers actually monitor, control and coordinate their projects and lead to a better understanding of requirements for tools to assist them.

Further research could also be undertaken to investigate the effectiveness of each mechanism or the reasons for their choice. While some mechanisms might be favoured in more formal software development projects there is little data available on the benefits of the mechanism compared to the cost of employing it.

\section{Bibliography}

Addison, T. and Vallabh, S. (2002), "Controlling software project risks: an empirical study of methods used by experienced project managers", Proceedings of the 2002 annual research conference of the South African institute of computer scientists and information technologists on Enablement through technology, Port Elizabeth, South African Institute for Computer Scientists and Information Technologists, pp. 128-140

Adler, P. S. (1995), "Interdepartmental Interdependence and Coordination: The Case of the Design/Manufacturing Interface." Organization Science, Vol.6, no 2, pp. 147-167.

Al-Jibouri, S. H. (2003), "Monitoring systems and their effectiveness for project cost control in construction", International Journal of Project Management, Vol.21, no 2, pp. $145-154$.

Andres, H. P. and Zmud, R. W. (2002), "A Contingency Approach to Software Project Coordination", Journal of Management Information Systems, Vol.18, no 3, pp. 41-70.

Burke, R. (2003), Project Management: Planning and Control Techniques., Burke Publishing, Tokai, South Africa, 4th ed

Carmel, E. (1999), Global Software Teams: Collaborating Across Borders and Time Zones, Prentice Hall PTR, Upper Saddle River

Choudhury, V. and Sabherwal, R. (2003), "Portfolios of control in outsourced software development projects." Information Systems Research, Vol.14, no 3, pp. 291-315.

Cleland, D. I. and Ireland, L. R. (2002), Project management: Strategic Design and Implementation, McGraw-Hill, 4th ed

Crowston, K. and Kammerer, E. E. (1998), "Coordination and collective mind in software requirements development", IBM Systems Journal, Vol.37, no 2, pp. 227-245.

Crowston, K. G. (1991), Towards a Coordination Cookbook: Recipes for Multi-Agent Action, A thesis submitted to Alfred P. Sloan School of Management, Massachusetts Institute of Technology, Boston 
Davies, R. and Saunders, R. (1988), "Applying systems theory to project management problems", International Journal of Project Management, Vol.6, no 1, pp. 19-26.

Dumke, R. R. and Winkler, A. S. (1997), "Managing the component-based software engineering with metrics", Proceedings Fifth International Symposium on Assessment of Software Tools and Technologies, pp. 104-110

Eisenhardt, K. M. (1985), "Control: Organizational and Economic Approaches", Management Science, Vol.31, no 2, pp. 134-148.

Eisenhardt, K. M. (1989), "Agency Theory: An Assessment and Review", Academy of Management Review, Vol.14, no 1, pp. 57-74.

Faraj, S. and Sproull, L. (2000), "Coordinating Expertise in Software Development Teams." Management Science, Vol.46, no 12, pp. 1554-1568.

Fenton, N. E. (2000), "Software metrics: roadmap", International Conference on Software Engineering, Limerick, ACM Press, pp. 357-370

Flamholtz, E. G., Das, T. K. and Tsui, A. S. (1985), "Toward an integrative framework of organizational control", Accounting, Organizations and Society, Vol.10, no 1, pp. 3550 .

Hamilton, R. D., III and Kashlak, R. J. (1999), "National Influences on Multinational Corporation Control System Selection", Management International Review, Vol.39, no 2, pp. 167-189.

Henderson, J. C. and Lee, S. (1992), "Managing I/S Design Teams: A control Theories Perspective", Management Science, Vol.38, no 6, pp. 757-777.

Hughes, B. and Cotterell, M. (1999), Software Project Management, McGraw-Hill, London

International Standards Organization, ISO 15504-3:2004 - Information technology - Process assessment - Part 3: Guidance on performing an assessment

Kerzner, H. (1998), Project Management: A Systems Approach to Planning, Scheduling, and Controlling., John Wiley \& Sons, Inc, New York, 6 ed

Kirsch, L. J. (1996), "The Management of Complex Tasks in Organizations: Controlling the Systems Development Process." Organization Science, Vol.7, no 1, pp. 1-22.

Kitchenham, B. (1996), Software Metrics: Measurement for Software Process Improvement, NCC Blackwell Ltd

Kitchenham, B. A., Hughes, R. T. and Linkman, S. G. (2001), "Modeling software measurement data", IEEE Transactions on Software Engineering, Vol.27, no 9, pp. 788-804.

Kraut, R. E. and Streeter, L. A. (1995), "Coordination in software development", Communications of the ACM, Vol.38, no 3, pp. 69-81.

Lacity, M. C. and Janson, M. A. (1994), "Understanding qualitative data: A framework of test analysis methods." Journal of Management Information Systems, Vol.11, no 2, pp. $137-155$.

Leedy, P. D. and Ormrod, J. E. (2001), Practical Research: Planning and Design, Merrill Prentice Hall, 7th ed

Malone, T. W. and Crowston, K. (1994), "The interdisciplinary study of coordination", ACM Computing Surveys, Vol.26, no 1, pp. 87-119.

McGarry, J., Card, D., Jones, C., Layman, B., Clark, E., Dean, J. and Hall, F. (2002), Practical Software Measurement, Addison-Wesley 
Navon, R. and Goldschmidt, E. (2003), "Monitoring labor inputs: automated-data-collection model and enabling technologies", Automation in Construction, Vol.12, no 2, pp. 185-199.

Nidumolu, S. R. (1996), "A comparison of the structural contingency and risk-based perspectives on coordination in software development projects", Journal of Management Information Systems, Vol.13, no 2, pp. 77-113.

OGC (2002), Managing successful projects with PRINCE2., Office of Government Commerce, London, 3rd ed

Ouchi, W. G. (1979), "A Conceptual Framework for the Design of Organizational Control Mechanisms", Management Science, Vol.25, no 9, pp. 833-848.

Ouchi, W. G. and Maguire, M. A. (1975), "Organizational Control: Two Functions." Administrative Science Quarterly, Vol.20, no 4, pp. 559-569.

Project Management Institute (2000), A Guide to the Project Management Body of Knowledge, Project Management Institute

Raffo, D., Harrison, W. and Vandeville, J. (2000), "Coordinating Models and Metrics to Manage Software Projects", Software Process Improvement and Practice, Vol.5, pp. 159-168.

Royce, W. (1998), Software project management : a unified framework, Addison Wesley, Reading, MA

Sabherwal, R. (2003), "The evolution of coordination in outsourced software development projects: a comparison of client and vendor perspectives", Information and Organization, Vol.13, no 3, pp. 153-202.

Seaman, C. B. (1999), "Qualitative methods in empirical studies of software engineering", IEEE Transactions on Software Engineering, Vol.25, no 4, pp. 557-572.

Shumate, K. and Snyder, T. (1994), "Software project reporting: management, measurement, and process improvement", Annual International Conference on Ada, Baltimore, ACM Press, pp. 41-45

Wood, M., Daly, J., Miller, J. and Roper, M. (1999), "Multi-method research: An empirical investigation of object-oriented technology", Journal of Systems and Software, Vol.48, no 1, pp. 13-26.

Yin, R. K. (2003), Case Study Research: Design and Methods, Sage, Thousand Oaks, 3rd ed originally published 1984

Zhuge, H. (2002), "Knowledge flow management for distributed team software development", Knowledge-Based Systems, Vol.15, no 8, pp. 465-471.

Zmud, R. W. (1980), "Management of Large Software Development Efforts", MIS Quarterly, Vol.4, no 2, pp. 45-55. 